\title{
Patrimonios controversiales y educación ciudadana a través del museo en Educación Infantil
}

\author{
Elisa ARROYO MORA \\ José María CUENCA LÓPEZ
}

Datos de contacto:

Elisa Arroyo Mora

Universidad de Huelva

elisa.arroyo@uhu.ddi.es

José María Cuenca López

Universidad de Huelva

jcuenca@ddcc.uhu.es

Recibido: 30/09/2021

Aceptado: 16/11/2021

\section{RESUMEN}

La educación patrimonial se configura en la etapa de Educación Infantil como el marco idóneo para desarrollar experiencias educativas que integren los patrimonios controversiales a partir del museo para fomentar el conocimiento y valoración del entorno y la actuación sobre él y para promover las primeras formas de pensamiento reflexivo y crítico. Por esto, el presente trabajo se propone describir la Sala de Exposición Permanente de Arqueología del Museo de Huelva e inferir de lo que allí se expone su papel didáctico para el tratamiento de los patrimonios controversiales, así como recomendar una serie de propuestas didácticas tipo para su uso en esta etapa educativa. Para indagar sobre los elementos patrimoniales del museo y la forma en la que se presentan ante el público escolar, se ha hecho un análisis cualitativo de dicha sala a partir de la técnica de observación sistemática de contextos, utilizando como instrumento un sistema de categorías que permite clasificar la información obtenida en una hipótesis de progresión que va desde el nivel más simple de la educación patrimonial hasta el deseable. Como primeros resultados, se ha encontrado que el Museo de Huelva presenta sus contenidos desde un enfoque academicista y que carece de recursos y actividades que promuevan la interacción del alumnado infantil, por lo que es necesario que se diseñen propuestas educativas en las que el museo sea un recurso didáctico y un espacio donde generar controversia, debate e interacción.

PALABRAS CLAVE: Educación Infantil; educación patrimonial; patrimonios controversiales; museo; análisis cualitativo. 


\title{
Controversial heritage and citizenship education through the museum in Early Childhood Education
}

\begin{abstract}
Heritage education is configured in Early Childhood Education stage as the ideal framework to develop educational experiences that integrate the controversial heritage from the museum to promote knowledge and valuation of environment and to promote early forms of critical thinking. Therefore, this work aims to describe the hall of archaeology in the Museum of Huelva and infer its didactic role for teaching controversial heritage and to recommend several teaching activities for Early Childhood Education. To investigate heritage elements in the museum and the way they are presented, we have made a qualitative analysis using the technique of systematic observation of contexts, using as an instrument a system of categories that allows us to classify the data obtained in a progression hypothesis from a simple perspective of heritage education to the desirable one. As first results, we have found that the Museum of Huelva presents this heritage from an academic approach and it has passive resources and activities, thus it is necessary to design teaching units in which museum can be an educational resource and a place where it can be generated debates and interaction.
\end{abstract}

KEYWORDS: Early Childhood Education; heritage education; controversial heritage; museum; qualitative analysis.

\section{Introducción}

La gran crisis global a la que se enfrentan las diferentes sociedades en el plano económico, social, cultural, político y medioambiental llevan poniendo de manifiesto desde hace varias décadas la necesidad que promover actuaciones comunitarias e institucionales desde una perspectiva holística y transversal cuyo origen se desarrolle desde el ámbito legislativo y educativo. Con este fin, la Organización de las Naciones Unidas, en el marco de la Agenda 2030, estableció en 2015 los 17 Objetivos de Desarrollo Sostenible como herramienta de análisis de la realidad y como meta a alcanzar para garantizar un presente y un futuro sostenible para la totalidad de la ciudadanía global, relacionando la justicia social, el progreso de las comunidades, la igualdad de género y el cuidado medioambiental.

Tomando como referencia estos objetivos, la escuela debe, desde las primeras etapas educativas, fomentar en el alumnado formas iniciales de pensamiento reflexivo y crítico, a través de las preguntas y el fomento de la empatía mediante dramatizaciones y debates sencillos, para promover acciones diarias en el plano local con pretensiones a nivel global, construyendo, así, una ciudadanía democrática y participativa con capacidad de actuación para la transformación de su realidad.

De esta forma, a partir del aprendizaje desde el contexto próximo y el patrimonio de su entorno, tal y como se explicita en la Orden curricular de 5 de agosto de 2008, los 
niños y niñas de Educación Infantil podrán ir construyendo su propia identidad y entendiendo la cultura en la que viven. En este sentido, la educación patrimonial es esencial para la formación de la ciudadanía, pues el patrimonio es fundamental para el sentido de identidad y de pertenencia a una comunidad (Cuenca, 2014) y contribuye a la formación de una ciudadanía comprometida con la valoración y el respeto social de dicho patrimonio (Peinado, 2020).

Asimismo, la formación de una ciudadanía democrática y crítica con el progreso de su comunidad desde las primeras etapas educativas pasa por el entendimiento de los conflictos que surgen en torno al patrimonio, a los avances sociales y a la justicia ecológica.

\section{Educación patrimonial en Educación Infantil}

El patrimonio, tal y como afirma Hernández-Ríos (2018), es un alto concepto que acompaña a las personas durante toda su vida y los vínculos que se establecen con él son inmediatos, por lo que los niños y niñas mantienen una relación directa con las manifestaciones culturales de su entorno desde edades tempranas. A partir de su patrimonio, el alumnado de Educación Infantil comienza a descubrir y a construir su identidad (De los Reyes, 2011), por lo que la escuela, siendo un espacio cultural de la experiencia humana que pretende explorar la realidad para poder transformarla (Feliu et al., 2015), debe aprovechar las potencialidades de los elementos patrimoniales del contexto próximo para fomentar el desarrollo de la autonomía y del pensamiento reflexivo y divergente del alumnado, así como de su capacidad de acción sobre el entorno.

La educación patrimonial en la etapa de Educación Infantil debe partir del entorno social del alumnado y de los paisajes urbanos, donde se puede apreciar la intervención humana para trabajar la sensibilidad medioambiental en conexión con las acciones que perjudican o mejoran la naturaleza, el progreso y la justicia social (Miralles \& Molina, 2011). El paisaje, como construcción social, es parte de la cultura de las sociedades y su estudio nos remite a las tradiciones y modos de vida de las comunidades con respecto de los territorios, ya que "los paisajes culturales se configuran, pues, como una rica síntesis histórica, donde convergen naturaleza y manifestaciones humanas, pasado y presente, lo material y lo intangible, que pueden llegar a conformar paisajes de alto valor patrimonial" (Liceras, 2017, p. 120).

Según Peinado (2020), desde las primeras etapas educativas se debe aplicar la educación patrimonial con el fin de formar personas preparadas para respetar, valorar y comprender el patrimonio y para interpretar y analizar las dinámicas sociales de forma crítica. Esta finalidad educativa se puede conseguir si los contenidos patrimoniales se abordan en conexión con problemas sociales relevantes del contexto próximo del estudiantado de forma holística, integrando las diferentes tipologías patrimoniales para promover una mejor comprensión de la realidad sociocultural y medioambiental (Cuenca et al., 2020).

De esta forma, siendo el entorno urbano -la ciudad, el barrio, la calle- el primer entorno social donde los niños y niñas se inician en la vida de la comunidad, este es el escenario idóneo para comprender las dinámicas de la sociedad y para iniciarse en 
conductas de respeto, cuidado y conservación del patrimonio y del medioambiente (De los Reyes, 2011).

\section{Patrimonios controversiales y educación ciudadana}

Tal y como sostiene Bonilla (2018), es necesario implementar una educación socioambiental que enseñe respeto y protección por el medio para no seguir degradando los espacios naturales y que forme, en definitiva, personas responsables, comprometidas y críticas con la sostenibilidad de las comunidades. Para poder alcanzar una educación en la que los y las estudiantes adquieran un mayor compromiso con su entorno, la comprensión de los vínculos con el pasado y la reflexión sobre las posibles consecuencias de los actos en el presente y en el futuro, Estepa (2019) propone abordar en el aula los patrimonios controversiales, es decir, manifestaciones patrimoniales cuyo interés radica no en sus valores estéticos o medioambientales, sino en diversas causas que suscitan conflicto de carácter ideológico, político, económico o medioambiental. Este tipo de patrimonio tiene como fin, según este autor, propiciar en el alumnado la capacidad de reflexionar, de tener opinión propia y de analizar críticamente la realidad. La enseñanza de los patrimonios controversiales nos permite, en palabras de Estepa et al. (2021), trabajar problemas socioambientales relevantes desde una perspectiva ecosocial para la formación de una ciudadanía comprometida con la defensa y gestión de su patrimonio.

En este sentido, en la etapa de Educación Infantil, dada la complejidad del tratamiento los patrimoniales controversiales, es idóneo trabajar los valores patrimoniales de los paisajes naturales en la ciudad, entendidos como el territorio en el que se conforman las sociedades, sus costumbres, tradiciones y formas de vida (Liceras, 2017). Abordar en el aula los conflictos que se generan en la ciudad por la intervención humana en los espacios verdes puede contribuir al desarrollo de las primeras formas de participación ciudadana y activismo y hacer que el alumnado se convierta en protagonista de la vida urbana en pro de buscar un entorno habitable y sostenible para las personas y todas las formas de vida (Tudela, 2017).

De la clasificación que Estepa y Martín-Cáceres establecen de las diferentes tipologías de patrimonios controversiales para su uso en los procesos de enseñanza y aprendizaje, en el estudio que nos ocupa se han seleccionado los patrimonios interesados o "patrimonios en conflicto entre la lógica económica, la ecológica y la social” (2018, p. 80). Un claro ejemplo de patrimonio interesado son los cabezos de Huelva: formaciones geológicas similares a colinas o pequeñas montañas con un papel fundamental en el origen y configuración de la ciudad y cuyos yacimientos arqueológicos nos aportan una valiosa información sobre la actividad humana de civilizaciones pasadas y sobre los modos de vida que hoy día se dan en la ciudad (Garrido-Morillo \& Romero-Macías, 2010). Estos elementos del paisaje urbano de Huelva con tan alto valor patrimonial se encuentran desde hace décadas amenazados por diversos planes urbanísticos de la ciudad y suponen un conflicto económico, medioambiental e identitario cuyo uso didáctico pretende promover la formación de 
una ciudadanía crítica, consciente de su identidad, responsable de su patrimonio y empática y tolerante con los demás (Estepa \& Martín-Cáceres, 2020). Estepa et al. (2021) encuentran fundamental incluir conflictos patrimoniales en los procesos de enseñanza y aprendizaje para mejorar la interpretación sociohistórica de nuestra sociedad, así como la comprensión y transformación de la actualidad. En las primeras etapas educativas, las propuestas didácticas en torno a los patrimonios controversiales más exitosas serán aquellas que propicien el contacto directo con los elementos patrimoniales desde un enfoque de investigación escolar, sirviéndose de gran variedad de recursos y actividades (Cuenca, 2014).

Así, estaremos promoviendo desde la etapa de Educación Infantil las primeras formas de participación ciudadana en defensa de su propio patrimonio e identidad y desarrollando las primeras acciones de conocimiento del entorno y actuación sobre el mismo para la transformación socioambiental, en la línea con lo establecido en el ODS 11 -ciudades y comunidades sostenibles-, de la Agenda 2030.

\section{El museo como recurso didáctico}

El museo es un lugar idóneo para abordar la identidad cultural, el territorio y las emociones de manera participativa (Cuenca et al., 2020), pues los museos y centros de interpretación, según Hernández-Ríos (2018), son transmisores de una conciencia colectiva y cumplen un papel esencial en la transferencia del conocimiento y en la transformación social. Aunque el patrimonio arqueológico no es objeto directo de estudio en la etapa de Educación Infantil (Bonilla \& Navas, 2018), teniendo en cuenta que en el Museo de Huelva se exponen multitud de elementos de yacimientos arqueológicos de los diferentes cabezos que configuran la ciudad, la institución museística, en nuestro caso, tal y como afirman Jardón y Soler (2019), se configura como un espacio donde trabajar con los niños y niñas cuestiones en torno a la memoria colectiva, donde desarrollar un aprendizaje significativo e inclusivo y donde generar controversias y promover reflexiones sobre el pasado que se les presenta y sobre sus acciones en el presente y en el futuro.

Tal y como se establece en la Orden curricular de 5 de agosto de 2008, el museo actúa en Educación Infantil como recurso didáctico y como contenido en sí mismo y forma parte de una de las experiencias culturales que la escuela debe proporcionar al alumnado desde edades tempranas. Martín-Cáceres (2012) afirma que la escuela y el museo se complementan, pues el museo juega un papel fundamental como agente estructurador de propuestas didácticas basadas en metodologías activas (Cuenca \& Martín-Cáceres, 2009) y es un recurso clave en el diseño de experiencias educativas interdisciplinares y globalizadas que promuevan la reflexión, el pensamiento crítico y el aprendizaje significativo (García-Luque \& De la Cruz, 2018).

Tal y como afirma Escribano (2015), la visita al museo en la etapa Educación Infantil supone un acercamiento por parte del alumnado a los elementos patrimoniales y una forma de investigación sobre su propio medio, pues dichos elementos son soportes del pasado que favorecen la comprensión del presente (Santacana \& Llonch, 
2012). De este modo, se pueden abordar los conflictos ecológicos y del patrimonio natural y cultural a partir de las manifestaciones patrimoniales locales presentes en el museo desde una perspectiva identitaria y holística del patrimonio y a partir de actividades interactivas y un enfoque investigativo (Cuenca, 2014).

\section{Método}

El objetivo principal del estudio consiste en describir los elementos patrimoniales de Sala de Exposición de Arqueología del Museo de Huelva y su forma de comunicarse con el público escolar visitante e inferir de dicha descripción su papel didáctico para el tratamiento de los patrimonios controversiales en la Educación Infantil. Para ello, el trabajo presentado sigue una metodología cualitativa bajo un paradigma interpretativo o naturalista, pues se centra en el estudio de los significados de los elementos protagónicos en los procesos educativos, siendo en nuestro caso los elementos patrimoniales expuestos en el museo como recurso de enseñanza y aprendizaje. Esta metodología adopta un enfoque holístico y global de la situación con el fin de comprenderla en su totalidad (Latorre et al., 2003, p. 205). Esta es, según los citados autores, una percepción de la investigación que busca la objetividad en el ámbito de las descripciones utilizando criterios de evidencia y categorías analíticas dentro de los "acuerdos intersubjetivos del contexto educativo" (2003, p. 42), pues parte de la concepción de la educación como constructo social, sujeto a interpretaciones subjetivas y a los significados que le otorgan los equipos docentes y de investigación implicados en el estudio (Sabariego, 2016).

Con el fin de analizar los elementos mostrados en la Sala de Exposición Permanente de Arqueología del museo e interpretar la finalidad didáctica de su exposición, se ha utilizado la técnica de observación sistemática de contextos, término acuñado por Martín-Cáceres (2012, p. 172), y un análisis DAFO como herramienta de planificación estratégica (Wang, 2007), que nos permitirá diseñar propuestas didácticas realistas y enriquecedoras para Educación Infantil a través del museo.

Para guiar el diseño del instrumento de recogida de información y su análisis a partir de las técnicas mencionadas, nos servimos de un sistema de categorías (Tabla 1), cuya principal característica es que las categorías están formadas por variables que, a su vez, llevan asignados unos indicadores ordenados a modo de hipótesis de progresión desde lo más simple y básico a lo más complejo y deseable (Martín-Cáceres, 2012, p. 167). Esta hipótesis de progresión en educación patrimonial constituye el marco teórico-metodológico del proyecto de investigación en el que se enmarca este estudio y toma como referente el modelo de profesor-investigador de la hipótesis de progresión del desarrollo profesional establecida por Porlán y Rivero (1998) y sus bases teóricas se apoyan en la Phenomenography de Manton (1981). Nuestro sistema es una adaptación de los sistemas de categorías de los proyectos EPITEC y EPITEC 2 y en él toman especial relevancia las variables en relación con la metodología y finalidad educativa del museo para abordar la cuestión controversial de los cabezos de Huelva en la etapa de Educación Infantil. 
Tabla 1

Sistema de categorías de análisis

\begin{tabular}{|c|c|c|}
\hline CATEGORÍAS & SUBCATEGORÍAS & INDICADORES \\
\hline \multirow[t]{3}{*}{$\begin{array}{l}\text { 1. Concepto de } \\
\text { patrimonio }\end{array}$} & $\begin{array}{l}\text { Perspectiva de } \\
\text { patrimonio }\end{array}$ & $\begin{array}{l}\text { Fetichista-excepcionalista } \\
\text { Monumental } \\
\text { Estética } \\
\text { Temporal } \\
\text { Diversidad } \\
\text { Simbólico-identitaria }\end{array}$ \\
\hline & $\begin{array}{l}\text { Tipología } \\
\text { patrimonial }\end{array}$ & $\begin{array}{l}\text { Natural-Histórica-Artística } \\
\text { Etnológica } \\
\text { Científica-Tecnológica } \\
\text { Holística }\end{array}$ \\
\hline & $\begin{array}{l}\text { Tipología de } \\
\text { patrimonios } \\
\text { controversiales }\end{array}$ & $\begin{array}{l}\text { Antipatrimonio } \\
\text { Dilemas patrimoniales } \\
\text { Patrimonio de la crueldad } \\
\text { Patrimonios interesados } \\
\text { Patrimonios en femenino } \\
\text { Patrimonios sometidos } \\
\text { Patrimonios inclusivos } \\
\text { Patrimonios rescatados } \\
\text { Patrimonios en transición }\end{array}$ \\
\hline \multirow[t]{2}{*}{$\begin{array}{l}\text { 2. Finalidad } \\
\text { educativa }\end{array}$} & $\begin{array}{l}\text { Enfoque de la } \\
\text { propuesta }\end{array}$ & $\begin{array}{l}\text { Inteligencia emocional } \\
\text { Alfabetización científica y cultural } \\
\text { Educación ciudadana } \\
\text { Educación ambiental } \\
\text { Inteligencia territorial }\end{array}$ \\
\hline & $\begin{array}{l}\text { Finalidad educativa } \\
\text { de la propuesta }\end{array}$ & $\begin{array}{l}\text { Pensamiento crítico } \\
\text { Enfoque ecosocial } \\
\text { Formación ciudadanía global } \\
\text { Educación en y para el decrecimiento }\end{array}$ \\
\hline \multirow[t]{3}{*}{$\begin{array}{l}\text { 3. Metodología de } \\
\text { enseñanza }\end{array}$} & Tipo de recursos & $\begin{array}{l}\text { Pasivos tradicionales } \\
\text { Pasivos TIC } \\
\text { Activos tradicionales } \\
\text { Activos TIC }\end{array}$ \\
\hline & Tipo de actividades & $\begin{array}{l}\text { Complejidad de nivel cognitivo baja } \\
\text { Complejidad de nivel cognitivo analítico } \\
\text { Complejidad de nivel cognitivo sistémico }\end{array}$ \\
\hline & $\begin{array}{l}\text { Relación recurso- } \\
\text { alumnado }\end{array}$ & $\begin{array}{l}\text { Comunicación unidireccional } \\
\text { Comunicación bidireccional } \\
\text { Comunicación multidireccional }\end{array}$ \\
\hline \multirow[t]{2}{*}{$\begin{array}{l}\text { 4. Relación entre } \\
\text { patrimonio e } \\
\text { inteligencia } \\
\text { territorial }\end{array}$} & $\begin{array}{l}\text { Conexiones con el } \\
\text { entorno }\end{array}$ & $\begin{array}{l}\text { Sin conexión } \\
\text { Institucional } \\
\text { Territorial } \\
\text { Interterritorial }\end{array}$ \\
\hline & Visión del paisaje & $\begin{array}{l}\text { Musealizado } \\
\text { Sostenible } \\
\text { Cultural }\end{array}$ \\
\hline
\end{tabular}

Fuente: Instrumento adaptado de los proyectos I+D+i EPITEC y EPITEC 2 (Cuenca \& Estepa, 2017; Estepa \& Martín-Cáceres, 2018). 


\section{Resultados}

Con el fin de describir los elementos patrimoniales de Sala de Exposición de Arqueología del Museo de Huelva y su forma de comunicarse con el público escolar visitante e inferir de dicha descripción su papel didáctico para el tratamiento de los patrimonios controversiales -concretamente los cabezos de la ciudad de Huelva- en la Educación Infantil, en primer lugar, se ha cuantificado el número de vitrinas y elementos que aluden directamente a dichos monumentos naturales, advirtiendo una notable presencia de los mismos para, posteriormente, analizar cada categoría en relación al tratamiento de dichos elementos patrimoniales controversiales.

De las 63 vitrinas, todas sin enumerar, que se extienden a lo largo de la sala, se exponen piezas encontradas en los cabezos de la capital -con su correspondiente cartelería identificativa- en 17 de ellas, de las cuales 8 se dedican exclusivamente a la exposición y descripción de elementos provenientes de los cabezos de Huelva, de las culturas a las que pertenecían y del territorio donde fueron encontrados. De las 8 vitrinas mencionadas, 6 muestran piezas singulares y la historia de la Necrópolis de la Joya, situada en el cabezo con el que comparte nombre, dejando patente la importancia de dicho cabezo para la configuración de la ciudad y su cultura desde la presencia de la civilización fenicia.

La sala de exposición estudiada incluye una amplia colección de elementos del patrimonio arqueológico de toda la provincia de Huelva, de la que forman parte 80 municipios, muchos de ellos con grandes hallazgos provenientes de épocas desde el Paleolítico hasta la Edad Media, por lo que es preciso destacar que encontrar en el 27\% de sus vitrinas elementos relativos a los cabezos de la capital supone poder inferir la relevancia arqueológica y, por ende, cultural, de dichas formaciones geográficas desde la perspectiva de la institución museística.

\section{Categoría I: Concepto de patrimonio}

Para comenzar con el análisis del papel educativo del Museo de Huelva en el tratamiento de los patrimonios controversiales en la etapa de Educación Infantil, es preciso partir del objeto de enseñanza, es decir, qué elementos patrimoniales se exponen en él y por qué.

La primera subcategoría de análisis atiende a la perspectiva de patrimonio que se percibe desde la sala de arqueología, o lo que es lo mismo, por qué se considera que los elementos patrimoniales allí expuestos son realmente patrimonio de Huelva. En base a las piezas que se presentan en las diferentes vitrinas, se deduce una perspectiva fetichista-excepcionalista del patrimonio arqueológico hallado en los cabezos, pues en la cartelería descriptiva de los elementos se intuye la valoración de los mismos por su singularidad, por considerarse únicos. Un claro ejemplo de ello es la muestra y descripción de vasijas de la civilización griega asentada en Huelva, cuya arcilla es procedente de las canteras de Gibraleón y del Cabezo del Conquero. Además, la exaltación del lujo de los ajuares y del carro funerario de la tumba 17 de la Necrópolis del cabezo de la Joya transmiten también la escasez o rareza de esas piezas halladas en 
la ciudad y pertenecientes a la aristocracia fenicia. Otro ejemplo de ello es la forma especialmente iluminada y destacada con respecto del resto de vitrinas de los ídolos oculados y betilos, encontradas en el Seminario de Huelva, llanura se inserta en la zona del cabezo del Conquero (Imagen 1).

\section{Imagen 1}

Vitrina de ídolos oculados y betilos

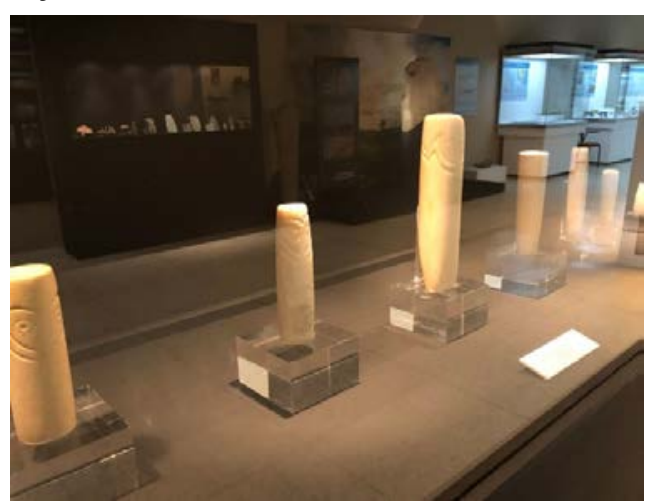

Fuente: Museo de Huelva, vitrina "Rituales y creencias de las sociedades del bronce".

Por su parte, en lo referente a la segunda subcategoría de análisis, en cuanto a la tipología patrimonial expuesta, el museo se encuentra entre el primer y segundo nivel de la hipótesis de progresión, pues, aunque la totalidad de las piezas parten del patrimonio histórico, más concretamente, arqueológico, en las diferentes vitrinas se presentan elementos de uso cotidiano significativos y pertenecientes a tradiciones de civilizaciones pasadas en relación con sus modos de vida y con la situación de los cabezos onubenses, lo que se podría considerar parte del patrimonio etnológico. Así, encontramos ajuares funerarios hallados en la Necrópolis de la Joya, urnas funerarias localizadas en el cabezo de la Esperanza (Imagen 2), figuras antropomorfas del cabezo de San Pedro (Imagen 3) o incluso pinturas murales de época Almohade -de los pocos hallazgos de la Edad Media en Huelva capital- también de la zona del cabezo de San Pedro (Imagen 4).

Por último, se ha añadido una subcategoría relativa a la tipología de patrimonios controversiales que se pueden advertir de la exposición y, a pesar de que desde el museo no parezca que se pretenda promover el pensamiento reflexivo y crítico en torno a las problemáticas suscitadas en relación con los cabezos onubenses, es innegable la notable presencia de hallazgos encontrados en este patrimonio que consideramos interesado, según la clasificación anteriormente descrita de Estepa y Martín-Cáceres (2018), por los conflictos entre la lógica económica, la ecológica y la social que provoca su gestión y conservación. Aunque no se puede afirmar que la intención de la institución museística sea defender los cabezos, la Sala de Exposición Permanente de Arqueología presenta numerosos elementos patrimoniales que pueden servir como justificación para su protección, por ser fundamentales en el origen y 
configuración de la ciudad de Huelva, así como en las costumbres y modos de vida de la ciudadanía.

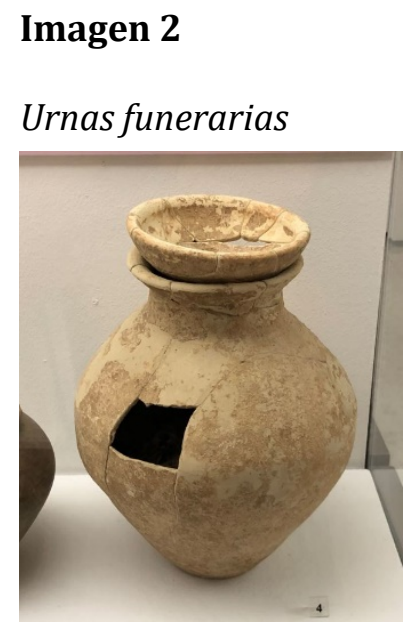

Imagen 3

Figuras antropomorfas

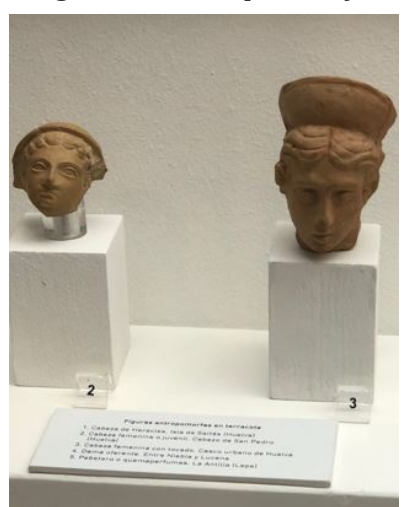

Imagen 4

Pintura mural

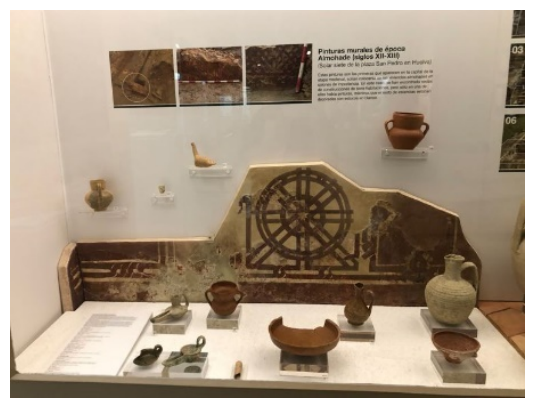

Fuente: Museo de Huelva, vitrinas "Ajuares funerarios", "Huelva postcolonial" y "Pinturas murales de la época Almohade".

\section{Categoría II: Finalidad educativa}

Para averiguar las pretensiones didácticas del Museo Huelva en base a los recursos expuestos en la sala de arqueología y su idoneidad para el trabajo a partir de los patrimonios controversiales, se han establecido dos subcategorías de análisis: enfoque y finalidad de la propuesta.

En primer lugar, localizamos el enfoque didáctico desde el que se disponen los recursos de la sala en el segundo nivel de la hipótesis de progresión, pues los elementos patrimoniales y su cartelería descriptiva correspondiente se enfocan a la alfabetización científica y cultural del visitante. Lejos de establecer comparaciones entre los útiles y abalorios de las sociedades desde la Prehistoria hasta la Edad Media con la cotidianeidad del alumnado o de promover su educación socioambiental, desde la Sala de Exposición Permanente de Arqueología se trata de dotar a las personas de conocimientos teóricos sobre la historia de la ciudad y de lenguaje técnico del patrimonio arqueológico. No obstante, cabe preguntarse el tipo de público -y la edad del mismo- al que van dirigidas dichas descripciones, pues una persona con carencias conceptuales acerca de la historia o la arqueología puede encontrar dificultades para la comprensión de diversos términos y más aún si se pretende diseñar una propuesta didáctica para la etapa de Educación Infantil a partir de ellas. Por ejemplo, en la vitrina "Huelva y Tarteso", dedicada a la exposición de diversas piezas de importación griega en Huelva, el elemento 2 se describe como "Fragmento de vaso con prótomo de vacuno"; el 3, como "Quemaperfumes ornitomorfo"; el 11, como "Escarabeo"; o el 12, como "Escaraboide" (Imagen 5). Por tanto, el enfoque de alfabetización cultural que se le da a la didáctica desde el museo no siempre podrá cumplir sus objetivos. 


\section{Imagen 5}

Cartel descriptivo de piezas de importación griega en Huelva

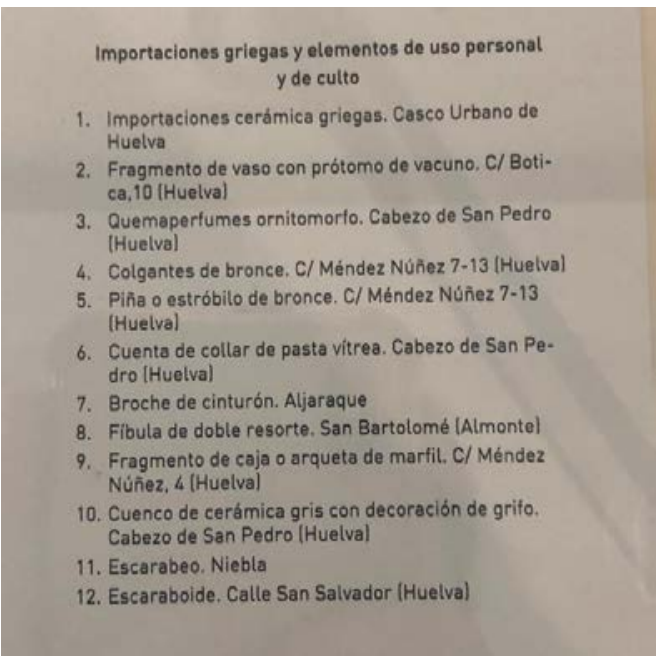

Fuente: Museo de Huelva, vitrina "Huelva y Tarteso".

En lo que respecta a la segunda subcategoría de análisis, referida a la finalidad educativa de la sala y sus recursos, se podría afirmar que esta tiende a tener un carácter exclusivamente academicista, pues promueve el conocimiento de hechos e informaciones de carácter cultural a través de ilustraciones, imágenes, recreaciones y aspectos relativamente anecdóticos. A lo largo de toda la sala se exponen elementos hallados en Huelva pertenecientes a épocas desde el Calcolítico, con herramientas encontradas en la zona del Seminario, hasta el periodo islámico, con elementos de uso cotidiano, como un candil encontrado en el cabezo de San Pedro. Sin embargo, en la cartelería asociada a los elementos patrimoniales y a la época a la que corresponden no se incluyen preguntas para que el visitante reflexione, cuestiones en torno a la acción humana sobre los entornos, sobre la conservación de estos patrimonios controversiales ni sobre conceptos relacionados con la sostenibilidad ni la identidad.

\section{Categoría III: Metodología de enseñanza}

Con el fin de analizar la forma en la que la institución museística expone las piezas halladas en los cabezos de Huelva, se han utilizado tres subcategorías de análisis que atienden a los recursos de los que se sirve, a la tipología de actividades que desarrolla $\mathrm{y}$ al tipo de comunicación que se establece entre el museo y, en nuestro caso, los escolares de Infantil.

En relación a la primera subcategoría de análisis, el tipo de recursos que pone el Museo de Huelva a disposición del público infantil se encuadraría en recursos tradicionales pasivos, ya que no implican la participación activa del alumnado, pues allí encontramos únicamente los elementos del patrimonio arqueológico y sus correspondientes carteles explicativos, algunos de ellos con información más completa y detallada a partir de recreaciones, dibujos o fotografías del entorno donde se localizan los yacimientos. 
En las 9 vitrinas en las que se incluyen piezas rescatadas de los cabezos entre otras localizadas en diferentes puntos de Huelva capital y su provincia solo se puede obtener información de pequeños carteles situados junto a cada elemento en los que se describe la pieza -y, en algunos casos, su uso y la época a la que perteneció- y se expone el lugar de extracción. Por su parte, la información presente en los carteles de las 8 vitrinas cuyos elementos pertenecen exclusivamente a yacimientos presentes en los cabezos es algo más completa, pues incluye, además de información detallada, fotografías reales de las excavaciones, de su localización y de las piezas en su contexto, así como recreaciones de elementos al completo y de mapas físicos de los cabezos a escala. Por ejemplo, en el caso de las vitrinas dedicadas a la Necrópolis de la Joya, en los carteles descriptivos incluyen fotografías reales de alguna de las tumbas y recrean uno de los carros funerarios (Imagen 6) o sitúan dicho emplazamiento con respecto de la ciudad actual (Imagen 7). En una vitrina referida a la producción cerámica, por su parte, incluye, además de piezas originales de la civilización griega asentada en la ciudad de Huelva, cartelería descriptiva con recreaciones de dichos vasos cerámicos e imágenes reales y actuales del cabezo del Conquero (Imagen 8).

\section{$\begin{array}{lll}\text { Imagen } 6 & \text { Imagen } 7 & \text { Imagen } 8\end{array}$}

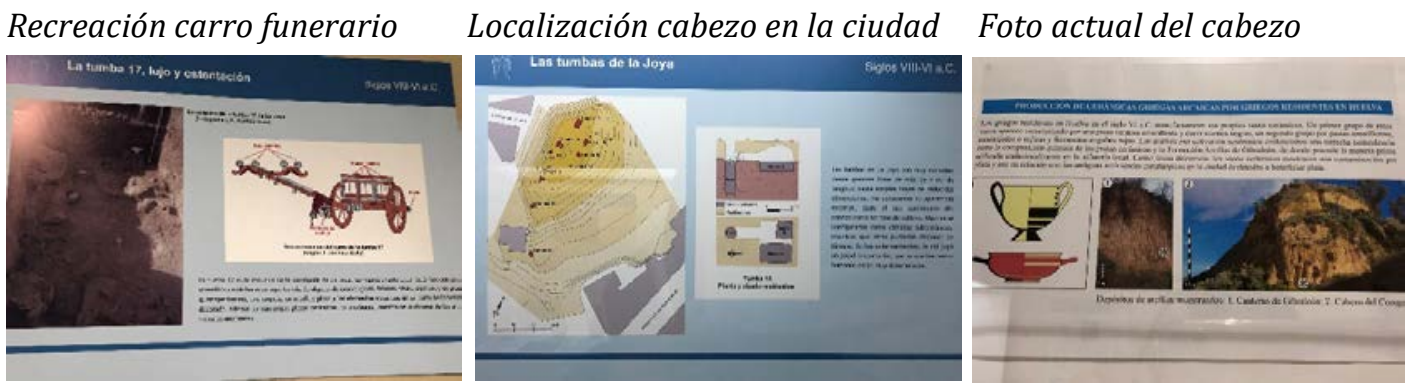

Fuente: Museo de Huelva, carteles de las vitrinas "La tumba 17, lujo y ostentación”, "Las tumbas de la Joya" y "Producción de cerámica griega".

Por otro lado, en lo que respecta a la segunda subcategoría de análisis, que alude al tipo de actividades que se desarrollan en la sala de arqueología, se puede percibir que estas se localizan en el primer nivel de la hipótesis de progresión, pues la complejidad de nivel cognitivo que requieren es baja. La visita habitual al museo se realiza de forma autónoma, por lo que la compresión de los elementos patrimoniales que allí se presentan y de la época y civilización a la que pertenecieron solo puede lograrse a través de la observación y la lectura de la cartelería informativa, es decir, solo se proponen ejercicios básicos de descripción teórica. En el caso concreto del alumnado de Educación Infantil, recién iniciado en el proceso de lecto-escritura, los únicos ejercicios posibles a realizar se basan en la observación de las piezas y el diálogo en torno a ellas, por lo que la funcionalidad de la visita solo vendría dada con una propuesta didáctica experiencial por parte del docente o de gestores patrimoniales.

En estrecha vinculación con los recursos y actividades del museo, la tercera subcategoría hace referencia al tipo de relación que se establece entre los elementos patrimoniales y recursos del museo con los estudiantes. Al encontrarnos ante recursos pasivos y ejercicios teóricos simples, la comunicación entre emisor y receptor es 
unidireccional, pues solo se aprecia un monólogo escrito por parte del museo y una interacción inexistente sin posibilidad de respuesta por parte del alumnado.

\section{Categoría IV: Relación entre el patrimonio y la inteligencia territorial}

Para conocer si la Sala de Exposición Permanente de Arqueología fomenta la adquisición de una inteligencia -y competencia- que promueva en el alumnado la reflexión y la movilización del conocimiento en pro de acciones ciudadanas que garanticen la sostenibilidad social y ecológica de la ciudad de Huelva a partir de la defensa de los cabezos, se han establecido dos subcategorías de análisis.

En primer lugar, en relación con qué visión del paisaje natural y cultural urbano se transmite desde el patrimonio mostrado, se percibe que, tanto los elementos patrimoniales como sus descripciones e imágenes asociadas promueven la percepción de los cabezos como una foto fija, inalterable e inamovible. Esta visión musealizada del paisaje, la cual se corresponde con el primer nivel de la hipótesis de progresión, ignora los cambios naturales y culturales que han sufrido los cabezos desde el origen de la ciudad, los planes urbanísticos que los amenazan, las propuestas de las asociaciones de participación ciudadana en defensa de los cabezos y las problemáticas políticas y sociales surgidas en torno a la gestión de los yacimientos arqueológicos que allí se emplazan.

Sin embargo, en lo relativo a la segunda subcategoría de análisis, la conexión que se muestra desde el museo entre el patrimonio y el entorno se asocia a una visión interterritorial -nivel más alto y deseable de la hipótesis de progresión-, pues relaciona los bienes patrimoniales hallados en Huelva y sus cabezos con la presencia de las diferentes civilizaciones en el territorio y con la consideración de la ciudad como un punto clave para el intercambio comercial con otras regiones y zonas de Europa, logrando un flujo cultural entre comunidades (Imagen 9).

\section{Imagen 9}

Cartel relaciones comerciales y culturales de Huelva y provincia con otras culturas mediterráneas

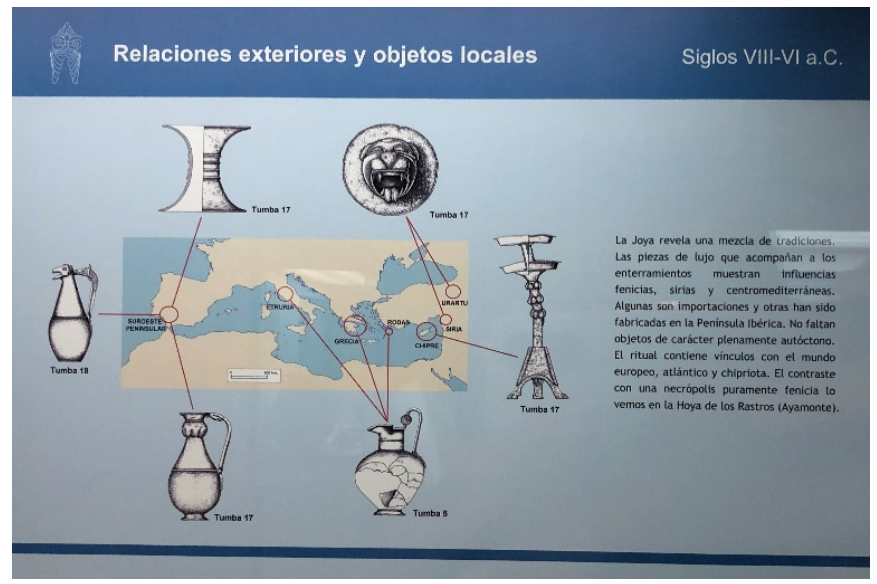

Fuente: Museo de Huelva, cartel de vitrina "Relaciones exteriores y objetos locales". 


\section{Síntesis de resultados: análisis DAFO}

De la descripción pormenorizada de las secciones del Museo de Huelva que se ocupa de los yacimientos arqueológicos localizados en los cabezos en base a las categorías y subcategorías de análisis se pueden extraer una serie de ideas en forma de debilidades, amenazas, fortalezas y oportunidades para el diseño de futuras propuestas didácticas para la etapa de Educación Infantil, a través del análisis DAFO (Tabla 2).

\section{Tabla 2}

Descripción de debilidades, amenazas, fortalezas y oportunidades del papel didáctico del museo para Educación Infantil: análisis DAFO

\begin{tabular}{|c|c|}
\hline DEBILIDADES: & AMENAZAS: \\
\hline $\begin{array}{l}\text {-Comunicación unidireccional con los } \\
\text { visitantes. } \\
\text {-Escasez de alusiones a la identidad cultural } \\
\text { de la ciudad y a las controversias generadas } \\
\text { en torno al patrimonio. } \\
\text {-Utilización de tecnicismos y palabras de } \\
\text { difícil comprensión para el alumnado de } \\
\text { Educación Infantil. } \\
\text {-Actividades y recursos pasivos sin } \\
\text { posibilidad de interacción. } \\
\text {-Inexistencia de recursos TIC interactivos } \\
\text { para público infantil. } \\
\text {-Enfoque científico sin cabida a la reflexión y } \\
\text { la crítica. }\end{array}$ & $\begin{array}{l}\text {-Falta de presupuesto para la realización de } \\
\text { actividades externas con escolares. } \\
\text {-Inexistencia de financiación que garantice el } \\
\text { cambio de enfoque didáctico de la sala. } \\
\text {-Posible carencia formativa del personal del } \\
\text { museo en cuanto a la enseñanza y } \\
\text { aprendizaje de los patrimonios } \\
\text { controversiales. }\end{array}$ \\
\hline FORTAI & OPORTUNIDADES: \\
\hline $\begin{array}{l}\text {-Cantidad y calidad de elementos del } \\
\text { patrimonio arqueológico proveniente de los } \\
\text { cabezos de Huelva. } \\
\text {-Existencia de piezas del patrimonio } \\
\text { etnológico. } \\
\text {-Presencia de cartelería con imágenes, } \\
\text { recreaciones, mapas y fotografías de las } \\
\text { piezas en su contexto. } \\
\text {-Conexión interterritorial con el entorno } \\
\text { (valoración de la diversidad y la } \\
\text { interculturalidad). }\end{array}$ & $\begin{array}{l}\text {-Posibilidad de introducir cuestiones } \\
\text { controvertidas en torno a los patrimonios } \\
\text { interesados. } \\
\text {-Posibilidad de establecer conexiones entre } \\
\text { los modos de vida pasados y actuales del } \\
\text { alumnado de Infantil a través del patrimonio } \\
\text { etnológico. } \\
\text {-Posibilidad de desarrollo de actividades } \\
\text { interactivas con niños y niñas a través de } \\
\text { empresas de gestión cultural. } \\
\text {-Posibilidad de enfocar la visita hacia una } \\
\text { educación ecosocial para la ciudadanía global } \\
\text { a partir de los elementos patrimoniales } \\
\text { expuestos. }\end{array}$ \\
\hline
\end{tabular}

Fuente: Elaboración propia. 


\section{Discusión y conclusiones}

El presente trabajo ha explorado las posibilidades educativas de la exposición de arqueología del museo para el tratamiento de los patrimonios interesados en la etapa de Educación Infantil. Para ello, se ha hecho una descripción pormenorizada de los elementos patrimoniales que se exponen en dicha sala y el modo en el que se establece la comunicación museo-alumnado. Teniendo en cuenta que, tal y como sostiene Martín-Cáceres (2012, p. 156), no existe personal encargado de la difusión en el Museo de Huelva y que el desarrollo de las actividades educativas en el mismo depende de la contratación de empresas de gestión cultural o de los equipos docentes de los centros educativos, el análisis descrito en este estudio se ha llevado a cabo mediante la observación sistemática de contextos -término acuñado por esta misma autora-, directamente en la Sala de Exposición Permanente de Arqueología.

Partiendo de la primera categoría de análisis, referida a qué patrimonio se expone en el museo, en la categoría de tipología de patrimonio que se expone y en la de perspectiva del mismo que se infiere de su observación sistemática, la sala de arqueología se localiza en los primeros niveles de la hipótesis de progresión propuesta, pues encontramos nulas referencias a la identidad onubense en los elementos patrimoniales, prácticamente todos de carácter histórico. En este sentido, Santacana y Llonch (2012) hacen referencia a los objetos museísticos no solo como piezas clave para conocer la historia, sino también como elementos para comprender el pasado $y$, en base a él, las dinámicas sociales del presente y las controversias generadas en torno al patrimonio, lo cual es relevante para la construcción de la identidad de las comunidades y, en nuestro caso, del alumnado de Infantil. Otros estudios sobre museos y sus programas educativos encuentran, del mismo modo, pocas exposiciones del patrimonio con respecto de su potencial para el desarrollo de relaciones identitarias o que hagan uso de la reapropiación del término para el empoderamiento del público visitante y ninguna propuesta que pretenda la formación de la ciudadanía desde una perspectiva sociocrítica (Aso et al., 2016; Cuenca et al., 2014).

Sin embargo, tal y como expresan Estepa y Martín-Cáceres (2018), y teniendo en cuenta la notable presencia de elementos patrimoniales presentes en el museo y cuyo origen son los cabezos de Huelva, en tanto que patrimonios controversiales interesados, sería conveniente que se diseñaran propuestas educativas en torno a este tipo de patrimonio para promover la reflexión en el alumnado de Educación Infantil, la valoración de aquellas manifestaciones relevantes para la identidad de su comunidad y la defensa del patrimonio natural de la ciudad como forma de protección de la naturaleza.

Además, con el fin de promover las primeras formas de pensamiento reflexivo, divergente y crítico en los niños y niñas desde temprana edad, es esencial transmitir una visión del paisaje desde una perspectiva cultural y holística, mostrando la intervención humana sobre el medio y abordando las acciones individuales y colectivas que benefician y perjudican el entorno para despertar la sensibilidad medioambiental del alumnado (Miralles \& Molina, 2011). En el Museo de Huelva, por el contrario, percibimos una visión musealizada de los cabezos de Huelva, ignorando la capacidad que tiene la institución museística de promover la sensibilización, valoración y 
socialización del patrimonio (Fontal \& Ibáñez-Etxeberria, 2017) que despierte el interés y la responsabilidad del alumnado en la defensa del mismo. El museo, siguiendo esta idea, debería mostrar los cabezos como la memoria y la historia de los pueblos que han configurado la ciudad de Huelva desde la necesaria relación de reciprocidad entre la naturaleza y la cultura (Liceras, 2017), de modo que forme, desde las primeras etapas educativas, una ciudadanía que valore la naturaleza y que participe activamente en su comunidad para lograr un entorno mejor y más habitable (Tudela, 2017).

Por otra parte, la finalidad educativa de la sala de arqueología que se percibe de su exposición, la cual se corresponde con la alfabetización científica del visitante desde un enfoque academicista, parece insuficiente e insatisfactoria teniendo en cuenta la edad y el desarrollo madurativo del alumnado de las primeras etapas educativas donde el proceso de enseñanza y aprendizaje debe ser vivencial, activo y significativo (Cambil \& Romero, 2017), conectar con las experiencias cotidianas y con los intereses de los estudiantes y promover la movilización de nuevos saberes y su aplicación práctica a través del conflicto cognitivo y de las situaciones-problema (García-Luque \& De la Cruz, 2018).

Estas carencias en el plano didáctico del Museo de Huelva se perciben, además, en la presencia de recursos pasivos en forma de cartelería y los propios elementos patrimoniales y en la ausencia de comunicación, pues el nivel de interacción del público escolar con el patrimonio es prácticamente nulo (Martín-Cáceres, 2012). En este sentido, se aprecia que en los museos permanece un modelo de comunicación didáctica tradicional alejado de propuestas interactivas (Cuenca et al., 2014) que no contempla el uso de recursos TIC interactivos que tantas posibilidades y potencialidades ofrecen para las propuestas didácticas en torno al patrimonio arqueológico, su entorno y los conflictos que pueden derivar de su contexto y su conservación (Ibáñez-Etxeberria et al., 2014).

Del mismo modo, sin un diseño didáctico realizado por docentes o por empresas de gestión cultural, es improbable que el estudiantado de Educación Infantil integre aprendizajes significativos en su visita a la sala de arqueología, pues las actividades posibles a realizar en ella se reducen a la observación de los elementos patrimoniales y su cartelería, teniendo en cuenta que a esta edad el alumnado está recién iniciado en el proceso de lecto-escritura. Escribano y Molina (2015) proponen que, en esta etapa, lo idóneo es desarrollar en el museo actividades de indagación y manipulación de los objetos o de reproducciones fieles para favorecer el aprendizaje por descubrimiento desde lo lúdico (Miralles \& Rivero, 2012), así como la formulación de preguntas y reflexiones en torno a la protección de su patrimonio.

\section{Propuestas para el tratamiento de los patrimonios controversiales en Educación Infantil a partir del museo.}

La educación patrimonial y el tratamiento de los patrimonios controversiales deben llevarse a cabo en el aula de Educación Infantil desde la realización de proyectos integrales que despierten el sentido crítico con la conservación, la preservación y la difusión del patrimonio (Castro et al., 2021). Para ello, es preciso que se aborden cuestiones de la cotidianeidad de los estudiantes, promoviendo un aprendizaje 
experiencial y significativo, que se trabajen de forma explícita las emociones y las capacidades de cada alumno y alumna y que de dichos proyectos resulten producciones propias del alumnado que quieran comunicar y difundir ante las personas de su entorno.

A continuación, proponemos, a partir de la descripción del papel didáctico del Museo de Huelva y del análisis DAFO realizado en base a la sala de arqueología, una serie de dinámicas y actividades tipo que incluir en proyectos educativos para que, desde la etapa de Educación Infantil, se aborden cuestiones en torno a la ciudadanía y a la valoración y protección del patrimonio interesado a través del museo:

-Análisis histórico, estético, sociológico y funcional de las piezas del patrimonio arqueológico (Santacana \& Llonch, 2012). Si se establecen comparaciones de los objetos del museo con utensilios y elementos del día a día del alumnado, estos despertarán su interés y motivación por las civilizaciones que los utilizaban, así como la protección de los elementos del patrimonio arqueológico hallados en los cabezos.

-Reproducción con materiales manipulativos (arcilla, barro, plastilina, etc.) de los elementos del patrimonio arqueológico observados en el museo.

-Dramatización de diversas escenas de los modos de vida de civilizaciones pasadas en base a las herramientas expuestas en el museo.

-Creación de cartelería que incluya textos breves e imágenes y dibujos de los hallazgos en los yacimientos arqueológicos para reivindicar la protección del patrimonio interesado.

-Recreación en el aula de algún yacimiento arqueológico localizado en los paisajes amenazados.

-Indagación sobre la flora y la fauna presente en los espacios naturales de la ciudad en peligro por la planificación urbanística.

-Narración de cuentos sobre las civilizaciones pasadas que poblaron, configuraron y transformaron la ciudad.

-Realización de itinerarios didácticos en los espacios verdes de la ciudad y análisis de su situación de cuidado, limpieza, etc.

-Realización de mapas o planos sencillos en los que representar los patrimonios amenazados y la vida de la ciudad y su ciudadanía.

-Proyección de vídeos interactivos sobre las civilizaciones pasadas y sus modos de vida.

-Juego de roles representando debates en los que intervienen los diferentes agentes de la ciudad (ayuntamiento, ciudadanía, empresas de construcción, plataformas ciudadanas) y se expresan puntos de vista y argumentos sobre la gestión de los patrimonios controversiales.

\section{Agradecimientos}

Esta publicación es parte del proyecto de $\mathrm{I}+\mathrm{D}+\mathrm{i}$ "Patrimonios controversiales para la formación ecosocial de la ciudadanía. Una investigación de educación patrimonial en la enseñanza reglada (EPITEC2)", referencia PID2020-116662GB-100, financiado por MCIN/AEI/10.13039/501100011033 y se enmarca en el Centro de Investigación en Pensamiento Contemporáneo e Innovación para el Desarrollo Social (COIDESO) de la Universidad de Huelva y en la RED-14: Red de Investigación en Enseñanza de las Ciencias Sociales, referencia RED2018/102336/T, financiada por MCIN/AEI/10.13039/501100011033. 


\section{Referencias}

Aso, B., García, S., Rivero, M. P., y Fontal, O. (2016). Estudio de caso de la acción educativa del Museu Afro Brasil de São Paulo. CLIO. History and History teaching, (42).

Bonilla, A. L. (2018). La actividad humana y los elementos que forman el entorno social y cultural. En A. L. Bonilla y Y. Guasch (coords.), Entorno, sociedad y cultura en Educación Infantil (pp. 165-176). Pirámide.

Bonilla, A. L., y Navas, E. (2018). El patrimonio arqueológico como recurso en Educación Infantil. En A.L. Bonilla y Y. Guasch (coords.), Entorno, sociedad y cultura en Educación Infantil (pp. 261-271). Pirámide.

Cambil, M. E., y Romero, G. (2017). Metodología por proyectos: un modelo innovador para la enseñanza y el aprendizaje del Patrimonio Cultural. En M.E. Cambil y A. Tudela (coords.), Educación y patrimonio cultural (pp. 61-80). Pirámide.

Castro, L., Rodríguez, J., y López-Facal, R. (2021). Educación patrimonial para una ciudadanía participativa. Evaluación de resultados de aprendizaje del alumnado en el programa Patrimonializarte. Revista Electrónica Interuniversitaria de Formación del Profesorado, 24(1), 205-219. https://doi.org/10.6018/reifop.444881

Cuenca, J. M. (2014). El papel del patrimonio en los centros educativos: hacia la socialización patrimonial. Tejuelo, (19) (2014), 76-96.

Cuenca, J. M., y Estepa, J. (2017). Educación patrimonial para la inteligencia territorial y emocional de la ciudadanía. MIDAS. Museus e estudos interdisciplinares, (8). http://dx.doi.org/10.4000/midas.1173.

Cuenca, J. M., y Martín-Cáceres, M. J. (2009) La ciudad actual a través de la ciudad histórica. Cuadernos de Pedagogía, (394), 67-69.

Cuenca, J. M., Martín-Cáceres, M. J., y Estepa, J. (2020). Buenas prácticas en educación infantil. Análisis de las conexiones entre emociones, territorio y ciudadanía. Aula Abierta, 49(1), 45-54. https://doi.org/10.17811/rifie.49.1.2020.45-54

Cuenca, J. M., Martín-Cáceres, M. J., Ibáñez-Etxeberria, A., y Fontal, O. (2014). La educación patrimonial en las instituciones patrimoniales españolas. Situación actual y perspectivas de futuro. CLIO. History and History teaching, (40).

De los Reyes, J. L. (2011). Didáctica de las ciencias sociales: vida cotidiana, conocimiento de sí mismo y autonomía personal. En P. Rivero (51ords51.), Didáctica de las Ciencias Sociales para Educación Infantil (pp. 65-88). Mira Editores.

Escribano, A. (2015). Utilización del patrimonio para el aprendizaje de la historia en educación infantil. Experiencia educativa “_Esta clase es un Museo!”. Pulso, (38), 179-205.

Estepa, J. (2019). Memoria, patrimonio y ciudadanía: una contribución desde una perspectiva didáctica. $P H,(96), 225-226$.

Estepa, J., y Martín-Cáceres, M.J. (2018). Competencia en conciencia y expresiones culturales y educación histórica. Patrimonios en conflicto y pensamiento crítico. En P. Miralles y C. J. Gómez (coords.), La educación histórica ante el reto de las competencias. Métodos, recursos y enfoques de enseñanza (pp. 75-86). Octaedro. 
Estepa, J., y Martín-Cáceres, M.J. (2020). Heritage in conflict: a way to educate in a critical and participative citizenship. En E.J. Delgado-Algarra y J.M. Cuenca (coords.), Handbook of Research on Citizenship and Heritage Education (pp. 4355). IGI Global.

Estepa, J., Cuenca, J. M., y Martín-Cáceres, M. J. (2021). Líneas futuras de trabajo desde el proyecto Epitec: patrimonios controversiales para una educación ecosocial de la ciudadanía. En J. M. Cuenca-López, Martín-Cáceres, M. J. y J. Estepa (eds.). Investigación y experiencias en Educación Patrimonial entre la escuela y el museo. Territorio, emociones y ciudadanía (pp. 483-492). Trea.

Feliu, M., Jiménez-Torregrosa, L., Arbonés, G., Bardavio, A., y Calabuig, S. (2015). Ciencias sociales y educación infantil (3-6). Cuando despertó el mundo estaba allí. Graó.

Fontal, O. e Ibañez, A. (2015). Estrategias e instrumentos para la educación patrimonial en España. Educatio Siglo XXI, 33(1), 15-32. http://dx.doi.org/10.6018/j/222481

Fontal, O. e Ibáñez-Etxeberría, A. (2017). La investigación en Educación Patrimonial. Evolución y estado actual a través del análisis de indicadores de alto impacto. Revista de Educación, (375), 184-205.

García-Luque, A., y De la Cruz, A. (2018). Aprendizaje basado en proyectos como recurso en Educación Infantil. En A.L. Bonilla y Y. Guasch (coords.), Entorno, sociedad y cultura en Educación Infantil (pp. 195-220). Pirámide.

Garrido-Morillo, R., y Romero-Macías, E. (2010). Los cabezos de Huelva: patrimonio geológico y cultural. En E. Romero-Macías (coord.), Una apuesta por el desarrollo local sostenible (pp. 139-145). Servicio de publicaciones de la Universidad de Huelva.

Hernández-Ríos, M. L. (2018). Patrimonio cultural y Educación Infantil: del objeto al bien cultural. En A. L. Bonilla y Y. Guasch (coords.), Entorno, sociedad y cultura en Educación Infantil (pp. 147-164). Pirámide.

Ibáñez-Etxeberria, A., Vicent, N., Asensio, M., Cuenca, J. M., y Fontal, O. (2014). Learning in archaeological sites with mobile devices. Munibe Antropologia-Arkeologia, (65), 313-321.

Jardón, P., y Soler, B. (2019). La coeducación en los museos: otra perspectiva. En H. Rausell y M. Talavera (coords.), Género y didácticas. Una mirada crítica, una aproximación práctica (pp. 133-154). Tirant Humanidades.

Latorre, A., Del Rincón, D., y Arnal, J. (2003). Bases metodológicas de la investigación educativa. Ediciones Experiencia.

Liceras, A. (2017). Patrimonio y paisaje. En M. E. Cambil y A. Tudela (coords.), Educación y patrimonio cultural (pp. 119-134). Pirámide.

Manton, F. (1981). Phenomenography. Describing conceptions of the world around us. Instructional Science (10), 177-200.

Martín-Cáceres, M. J. (2012). La educación y la comunicación patrimonial: una mirada desde el Museo de Huelva. Tesis Doctoral. Universidad de Huelva. http://rabida.uhu.es/dspace/handle/10272/6048

Miralles, P., y Molina, S. (2011). Didáctica de las ciencias sociales para el área de conocimiento del entorno. En P. Rivero (coord.), Didáctica de las Ciencias Sociales 
para Educación Infantil (pp. 89-110). Mira Editores.

Miralles, P., y Rivero, P. (2012). Propuestas de innovación para la enseñanza de la historia en Educación Infantil. REIFOP. Revista Electrónica Interuniversitaria de Formación del Profesorado, 15 (1), 81-90.

Peinado, M. (2020). Del patrimonio a la ciudadanía en Educación Infantil. Investigación en la Escuela, (101), 48-57. https://doi.org/10.12795/IE.2020.i101.04

Porlán, R., y Rivero, A. (1988). El conocimiento de los profesores. Diada

Sabariego, M. (2016). La investigación educativa: Génesis, evolución y características. En R. Bisquerra (Coord.). Metodología de la investigación educativa (pp. 49-86). 5o Edición, Arco.

Santacana, J., y Llonch, N. (2012). Manual de didáctica del objeto en el museo. Trea.

Sarsby, A. (2016). SWOT análisis. A guide to SWOT for business studies students. Leadership Library.

Tudela, A. (2017). La ciudad en la memoria: desafíos para la educación patrimonial y cultural. En M. E. Cambil y A. Tudela (coords.), Educación y patrimonio cultural (págs. 177-199). Pirámide.

Wang, K.-C. (2007). A Process View of SWOT Analysis. Proceedings of the 51st Annual Meeting of the ISSS - 2007, Tokyo, Japan,51(2). Recuperado de: https://journals.isss.org/index.php/proceedings51st/article/view/470 